(C) 2018 Uniwersytet Warszawski/ University of Warsaw. Wydanie w otwartym dostępie na licencji CC BY-NC-ND (https://creativecommons.org/licenses/by-nc-nd/4.0/deed.pl). This is an open access article under the CC BY-NC-ND license (http://creativecommons.org/licenses/by-nc-nd/4.0/).

Applied Linguistics Papers 25/ 3, 2018, 175-179

\title{
The 6th Polish Eye Tracking Conference Report
}

The 6th Polish Eye Tracking Conference took place on 15-17 June 2018 in Warsaw in the building of the Faculty of Applied Linguistics, University of Warsaw. Two international projects - the 6th Polish Eye Tracking Conference and the 2nd EARLI SIG 27 Conference (27 Special Interest Group of the European Association of Research on Learning and Instruction) - were combined in the framework of one convention. The representatives of the University of Warsaw (Poland), the Catholic University of Lublin (Poland), the Open University of the Netherlands, and the Neuro Device company joined their efforts to organise this large-scale event. The working language of the conference was English. 36 presentations including 5 keynote speeches were divided between 8 different sections and 35 posters were displayed during the poster session.

Every year the Polish Eye Tracking Conference not only provides an opportunity to share and expand knowledge in the field, but also constitutes a large platform for networking and making business contacts. It is also a tremendous chance to learn about state-of-the-art equipment. Professionals with first-hand experience presented eye tracking devices throughout the conference. This exceptional interdisciplinary conference gathered together eye-tracking enthusiasts who use this methodology in various areas from linguistics research to medicine.

On the first day of the conference, the guests could take part in two complimentary workshops in order to explore multiple facets of eye tracking. The first workshop conducted by Andrew Thomas and Mark Crawley from Rogue Resolutions was on the use of Transcranial magnetic stimulation (TMS) in eye tracking studies. The aim of the demonstration was to show how TMS can affect the ability to execute basic eye movements. The second workshop offered by Róża Budzyńska from Neuro Device and Aleksandar Dimov from BIOPAC was devoted to the co-registration of psychophysiological and eye tracking data and covered essential aspects of data recording, synchronisation and analysis.

The conference opened its doors at 14:00 on Friday, the 15th of June. The first keynote speaker was Ernesto Panadero, Ph.D., a researcher at the Developmental \& Educational Psychology Department at the Autonomous University of Madrid (Spain) and an Honorary Professor at the Centre for Research in Assessment and Digital Learning (CRADLE), Deakin University (Australia). He delivered a presentation on learning assessment. The second keynote presentation on an eye tracking study of English textbooks was given by Agnieszka Andrychowicz-Trojanowska, Ph.D., who is an Assistant Professor at the Institute of Specialised and Intercultural Communication, Faculty of Applied Linguistics at the University of Warsaw. Two keynote presentations were followed by a coffee break after which the conference was 
divided into two parallel sections (A and B) respectively devoted to technology and learning. Four presentations were delivered at section A: "Gaze Control of Movie Playback" by Jacek Matulewski, Ph.D. (Polish $d r$ hab.), "Automatic Mapping Coordinates Data from Eye Tracking Glasses to Reference Image" by Szymon Kupinski, "Deictic Gaze in Virtual Reality Environments" by Cengiz Acarturk, Ph.D. and "Foveated Rendering for Virtual Reality Goggles" by Radosław Mantiuk, Ph.D. (Polish $d r h a b$. inz.). Three presentations were given at section B (Learning) "Physiological Data as Unobtrusive Measures for Motivation and Self-Regulated Learning" by Moritz Niemann, Ph.D., "Integration or Disorientation: Double-sided Relation of Process Measures in Graph Comprehension Tasks" by Ulrich Ludewig and "Children's Visual-Cognitive Behaviours When Completing a Graph Task: Machine Learning Analyses of Eye-Tracking Data" by Enrique Garcia MorenoEsteva, Ph.D; they were followed by a business meeting. Afterwards, the guests of the conference met at a welcoming banquet at the rooftop terrace of the conference venue.

The second day began with two keynote presentations delivered by Jacob L. Orquin, Ph.D., an Associate Professor at the Department of Management at Aarhus University and Katharina Scheiter, Ph.D., Head of the Multiple Representations Lab at the Leibniz-Institut für Wissensmedien and Full Professor for Empirical Research on Learning and Instruction at the University of Tübingen in Germany. The presentation of Jacob L. Orquin was devoted to the threats of the validity of eye movement research and Katharina Scheiter focused on offline and online gaze-based interventions in both fundamental lab research and real-world learning tools. As on the previous day, there were two sections after the keynote speakers' presentations. The following presentations were given at the Psychology section: "Eye Movement Correlates of Accurate Recognition of Harmony in Paintings" by Piotr Francuz, Assoc. Prof. (Polish prof. $d r$ hab.), "Interaction with Exhibition in a Science Centre a Multistage Eye Tracking Research in Natural Settings" by Justyna Żurawska and Olga Borkowska, "Eye tracking survey in the Warsaw Uprising Museum" by Marta Rusnak, Ph.D. (Polish $d r$ inż. arch.), "Customers' Journey in the Shopping Environment - Mobile Eye Tracking as a Valuable Measurement to Verify Best Practice During Purchasing Process" by Tomasz Soluch. The following presentations were delivered at the Reading section: "Comprehension of Multiple Digital Documents Connected Via Inter-textual Versus Extra-textual Hyperlinks" by Eliane Segers, Ph.D., "It Is Not Only About the Depth of Processing: What If Eye Am Not Interested In the Text?" by Leen Catrysse, Ph.D., "Reading With the Eyes and Under the Skin: Processing Conflicting Online Documents" by Lucia Mason, Ph.D., "Learning About Controversial Scientific Issues On the Internet: Relations Between Attention to Source Information and Sourcing and Argumentation in Essays" by Yvonne Kammerer, Ph.D.

Some of the conversations that started during the panel discussions were often continued in a more informal atmosphere at the lunch break that followed. When it finished, the attention of the participants was turned on the floor above the conference rooms, where the poster session was organised. The 35 posters displayed were devoted to multifarious subjects varying from marketing and teacher-learner interaction to neuroscience and usability of particular eye tracking indicators for 
further research. The one-hour session constituted an opportunity for young researchers to consult their preliminary findings with experienced and renowned specialists in various fields.

The two sections of the last session of the second day of the conference were devoted to applied linguistics (A) and EEG/ log files analysis (B) respectively. In the first presentation of section A, Ewa Ramus, MSc (Neuro Device) described the possible use of eye tracking in supporting the therapy and diagnosis of children with the autism spectrum disorders. The next presentation ("Towards eye tracking methodology in linguistics: advantages and pitfalls") was given by Monika Płużyczka, Assoc. Prof. (University of Warsaw, Institute for Specialised and Intercultural Communication). She concentrated on the gradually increasing use of eye tracking in translation studies and applied linguistics as well as the new possibilities and risks that it entails. The following presentation, given by Dominik Kudła, MA and Maria Nikishina, MA (on behalf of a team from the Institute of Specialised and Intercultural Communication), was devoted to analysing sight translation performed by applied linguistics students with the use of eye tracking. Pre-translation reading was compared to sight translation from and into English, German, Russian and Polish. The presentation closing this section, titled "Modes of AVT and Audience Viewing Styles in Poland", was given by Olga Łabendowicz, MA (Department of Translation Studies, University of Łódź). She compared the ways of viewing professional and amateur subtitling provided to humorous scenes in American films. In the first presentation of section B, Christian Scharinger, Ph.D. (Leibniz-Institut für Wissensmedien, Tübingen), talked about the role of immersion in cognitive processing and learning while using virtual reality devices. The reactions of the participants his team measured using EEG and eye tracking equipment. In her presentation "Using EEG to Assess the Cognitive Process of Reading in Virtual Reality", Sarune Baceviciute, Ph.D. (Faculty of Psychology, University of Copenhagen), compared the cognitive processes occurring while reading a physical pamphlet in a book and as a VR text. The next presentation, given by professor Andreas Rausch (Faculty of Psychology and Education Sciences, University of Mannheim), was devoted to various approaches to $\log$ file analysis of computer-based learning and problem solving. In the presentation closing section B, professor Steffi Zander (Bauhaus-Universität Weimar) compared the individual differences in solving spatial tasks on mobile devices by male and female teenage students.

After the panel discussions, the participants went on a short tour around the central campus of the University of Warsaw, which finished with a visit to the Museum of the university and a brief lecture on its history. Then the conference participants went to the Pillared Hall at the building of the Faculty of History for a standing-party conference dinner.

The third day of the conference was opened with a keynote speech "FIFA 18 players - how do they feel and what do they see? Eye tracking, GSR/EDA, ECG and face tracking - research reconnaissance" by Tomasz Gackowski, Assoc. Prof. and Karolina Brylska, Ph.D. (Faculty of Journalism, Information and Book Studies, University of Warsaw). The talk presented the results of analysing the behaviour 
of video game players using several various psycho-physical indicators, such as heart rate, face expression, gaze patterns and electrodermal activity.

Following the coffee break, the participants once again divided into two sections - one devoted to applied linguistics (A) and one devoted to eye movement visualisations (B). Section A started with a talk by Małgorzata Szupica-Pyrzanowska, Ph.D. and Katarzyna Malesa, Ph.D. (Institute of Applied Linguistics, University of Warsaw). They spoke about the results of an eye tracking study into the relation between intensive linguistic training in foreign languages and the ability to detect lexical, inflectional and phonetically-conditioned orthographic errors in the mother tongue. Marcin Leśniak, Ph.D. (University of Wrocław). in his presentation. characterised the changes in oculomotor performance that occur in patients with poststroke neglect syndrome. Gaze behavior as an indicator for specific functions of multiple external representations while problem solving was described in her presentation closing section A by Sarah Malone, Ph.D. (Faculty of Education, Saarland University).

The first talk of section B by Thérése Eder, M.Sc., "Do eye movement visualisations foster the interpretation of radiology images and gaze behaviour of dental medicine students?", showed the results of anomaly detection tests of students provided with exemplary gaze patterns of experienced specialists. Tim van Marlen, M.Sc., in his presentation, compared the effectiveness of computer-based learning tasks performed after watching a performance-modelling video with and without the eye movement of the specialist. Margot van Wermeskerken, Ph.D. (Faculty of Education, Utrecht University), suggested a classification of patterns in visualizations of eye movements while performing a sorting task.

After the coffee break, the participants could choose one of the two symposia prepared by the Earli SIG 27 members. Symposium 1, chaired by Marjaana Puurtinen, was titled "Eye-tracking in music studies: Examples, best practices and what to avoid". The first speech was given by Marjaana Puurtinen, Ph.D. (University of Turku), and devoted to eye movements in performing rhythm notation. It was followed by a presentation by professor Hans Gruber (University of Regensburg), where the results of an eye-movement analysis of music educators preparing an arrangement for a group of students were shown. Natalia Chitalkina, M.Sc. (Faculty of teacher education, University of Turku), concentrated on eye-movement effects of added cognitive load in music reading. The last talk, "Eye movement processes in repeated reading of Finnish folk music", was given by Anna-Kaisa Ylitalo, Ph.D. (Faculty of Music, Art and Culture Studies, University of Jyväskylä).

Symposium 2, titled "Exploring Teachers' Gaze Behavior in the Classroom Using Mobile Eye Tracking", was chaired by Sharisse van Driel. It was opened by Nora McIntyre, Ph.D. (Department of Psychology, University of Sheffield), who investigated the reactivity effects in student-teacher communication using video materials, questionnaires and teacher eye-tracking. The presentation was followed by the talk "Exploring Teachers" Gaze Behavior in the Classroom Using Mobile Eye Tracking: Teacher's Gaze Behavior During a Mathematical Collaborative ProblemSolving Session" by Enrique Garcia Mereno-Esteva, Ph.D. (University of Helsinki). Sharisse van Driel, M.Sc. (Open University of the Netherlands, Heerlen), presented 
the role of eye movements in classroom management among preservice teachers, while Irene Skuballa, Ph.D. (New York University Abu Dhabi), commented on common gaze patterns among kindergarten teachers during instructional sessions.

When the two symposia ended, the members of the Scientific Committee officially closed the conference. The good-bye lunch was an occasion for the participants to continue some discussions begun at the conference and to exchange farewells.

\section{Dominik KUDŁA}

Uniwersytet Warszawski/ the University of Warsaw

E-mail: dominik_kudla@uw.edu.pl,

\section{Maria NIKISHINA}

Uniwersytet Warszawski/ the University of Warsaw

E-mail:m.nikishina@uw.edu.pl, 